\title{
Matrix metalloproteinase 12 promotes tumor propagation in the lung
}

\author{
Ezra Ella, PhD, ${ }^{a}$ Yaniv Harel, MSc, ${ }^{a}$ Michal Abraham, $\mathrm{PhD},{ }^{a}$ Hanna Wald, $\mathrm{PhD},{ }^{a}$ Ofra Benny, $\mathrm{PhD},{ }^{\mathrm{b}}$ \\ Adi Karsch-Bluman, MSc, ${ }^{b}$ Dive Vincent, $\mathrm{PhD},{ }^{\mathrm{c}}$ Devel Laurent, $\mathrm{PhD},{ }^{\mathrm{c}}$ Gail Amir, MD, ${ }_{\mathrm{e}}^{\mathrm{e}}$ Uzi Izhar, MD, \\ Oz M. Shapira, MD, ${ }^{d}$ David Yoon, BA, ${ }^{f}$ Hyun-Sung Lee, MD, PhD, ${ }^{f}$ David J. Sugarbaker, MD, ${ }^{f}$ \\ Bryan Burt, $\mathrm{MD},{ }^{\mathrm{f}}$ Amnon Peled, $\mathrm{PhD},{ }^{\mathrm{a}}$ and Ori Wald, $\mathrm{MD}, \mathrm{PhD}^{\mathrm{a}, \mathrm{d}}$
}

\section{ABSTRACT}

Objective: Past studies are inconsistent with regard to the role of matrix metalloproteinase 12 in lung tumorigenesis. This is due, in part, to differential tumorigenesis based on tumor-derived versus immune-derived matrix metalloproteinase 12 expression. Our study aims to thoroughly dissect the role of matrix metalloproteinase 12 in lung tumorigenesis.

Methods: We tested matrix metalloproteinase 12 expression and the association with prognosis using a tissue array and a published non-small cell lung cancer gene expression database. In addition, we characterized the contribution of matrix metalloproteinase 12 to tumor propagation in the lung using a series of in vitro and in vivo studies.

Results: Tumor cells of a diverse set of human lung cancers stained positive for matrix metalloproteinase 12, and high matrix metalloproteinase 12 mRNA levels in the tumor were associated with reduced survival. The lung microenvironment stimulated endogenous production of matrix metalloproteinase 12 in lung cancer cells (human 460 lung cancer cell line, Lewis lung carcinoma). In vitro, matrix metalloproteinase 12 knockout Lewis lung carcinoma and Lewis lung carcinoma cells had the same proliferation rate, but Lewis lung carcinoma showed increased invasiveness. In vivo, deficiency of matrix metalloproteinase 12 in Lewis lung carcinoma cells, but not in the host, reduced tumor growth and invasiveness.

Conclusions: We suggest that tumor cell-derived matrix metalloproteinase 12 promotes tumor propagation in the lung and that in the context of pulmonary malignancies matrix metalloproteinase 12 should further be tested as a potential novel therapeutic target. (J Thorac Cardiovasc Surg 2018;155:2164-75)

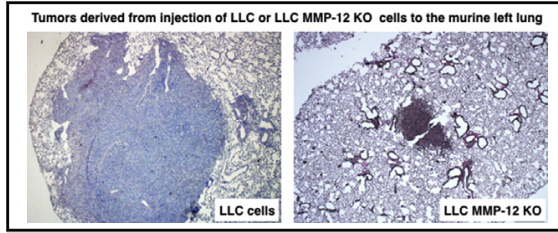

Representative tumors derived from the injection of LLC and LLC MMP-12 KO cells to the murine left lung.

\section{Central Message}

In the current work, we show that MMP-12 drives tumor propagation in the lung. We submit that MMP-12 is a novel therapeutic target in the context of pulmonary malignancies.

\section{Perspective}

Controversy exists regarding the role of MMP12 in lung tumorigenesis with past research showing that immune-derived MMP-12 is antitumorigenic and that tumor-derived MMP- 12 is protumorigenic. We test the role of MMP-12 in lung tumorigenesis. We show that in NSCLC, high MMP-12 mRNA levels correlate with reduced survival and that in an orthotopic model of the disease, MMP-12 promotes tumor growth.

See Editorial Commentaries pages 2176 and 2177.

See Editorial page 2162
From the a Goldyne Savad Institute of Gene Therapy, Hadassah University Hospital,

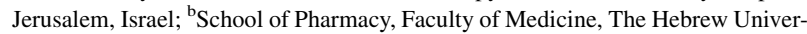
sity, Jerusalem, Israel; ${ }^{\mathrm{c} C E A}$ Saclay, SIMOPRO, Gif/Yvette, France; Departments of ${ }^{\mathrm{d} C a r d i o t h o r a c i c ~ S u r g e r y ~ a n d ~}{ }^{\mathrm{e} P a t h o l o g y, ~ H a d a s s a h ~ U n i v e r s i t y ~ H o s p i t a l, ~ J e r u s a-~}$ lem, Israel; and ${ }^{\mathrm{f} D i v i s i o n}$ of General Thoracic Surgery, Michael E. DeBakey Department of General Surgery, Baylor College of Medicine, Houston, Tex.

Read at the 97th Annual meeting of The American Association for Thoracic Surgery, Boston, Massachusetts, April 29-May 3, 2017.

Received for publication March 17, 2017; revisions received Nov 9, 2017; accepted for publication Nov 17, 2017; available ahead of print Feb 8, 2018.

Address for reprints: Ori Wald, MD, PhD, Department of Cardiothoracic Surgery, Hadassah Hebrew University Hospital, Jerusalem, Israel (E-mail: ori.wald@mail. huji.ac.il).

$0022-5223 / \$ 36.00$

Copyright $(\odot 2018$ by The American Association for Thoracic Surgery

https://doi.org/10.1016/j.jtcvs.2017.11.110
Matrix metalloproteinase 12 (MMP-12), also known as "macrophage elastase," is a metalloproteinase that cleaves elastin. ${ }^{1}$ It is produced by activated macrophages in premalignant lung diseases such as chronic obstructive

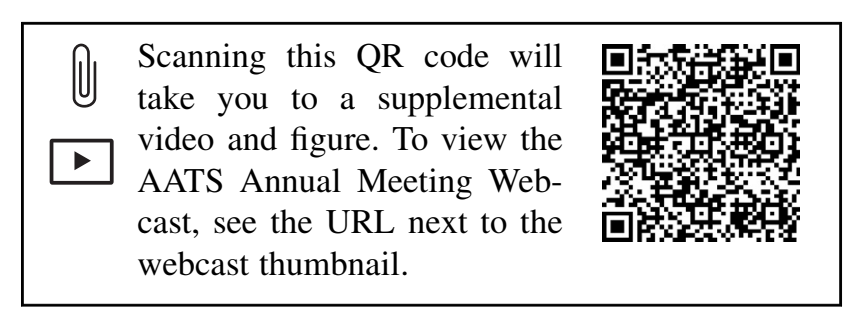




$$
\begin{aligned}
& \text { Abbreviations and Acronyms } \\
& \begin{aligned}
\text { ELISA } & =\text { enzyme-linked immunosorbent assay } \\
\text { FCS } & =\text { fetal calf serum } \\
\text { GFP } & =\text { green fluorescent protein } \\
\text { H460 } & =\text { human } 460 \text { lung cancer cell line } \\
\text { HPRT1 } & =\text { hypoxanthine } \\
& \text { phosphoribosyltransferase } 1 \\
\text { HR } & =\text { hazard ratio } \\
\text { KO } & =\text { knockout } \\
\text { LLC } & =\text { Lewis lung carcinoma } \\
\text { MMP-12 } & =\text { matrix metalloproteinase } 12 \\
\text { NSCLC } & =\text { non-small cell lung cancer } \\
\text { PCR } & =\text { polymerase chain reaction } \\
\text { RPMI } & =\text { Roswell Park Memorial Institute }
\end{aligned}
\end{aligned}
$$

pulmonary disease and emphysema. ${ }^{2}$ In these pathologic conditions, macrophage-driven overproduction of MMP12 is considered to promote excessive degradation of elastin and, consequently, to mediate irreversible parenchymal damage. ${ }^{3}$ Notably, MMP-12 is also highly expressed in primary malignant tumors of the lung. ${ }^{4,5}$ Yet, distinct from its well-documented role in the pathogenesis of chronic obstructive pulmonary disease and emphysema, the role of MMP-12 in human lung cancer pathogenesis remains largely unknown. ${ }^{6}$ Indeed, studies that looked at the expression and potential function of MMP-12 in early-stage non-small cell lung cancer (NSCLC) have yielded vastly inconsistent findings. For example, when characterizing the tissue localization of MMP-12 in the tumor, Acuff and colleagues ${ }^{7}$ found that MMP-12 is mainly expressed by tumor-infiltrating macrophages, whereas Hofmann and colleagues ${ }^{8,9}$ reported that these were the tumor epithelial cells themselves that were the main source of MMP-12 in the tumor. Further, when looking into the association between MMP-12 expression and NSCLC disease recurrence, Hofmann and colleagues, ${ }^{8,9}$ Cho and colleagues, ${ }^{10}$ and $\mathrm{Lv}$ and colleagues ${ }^{11}$ found that high MMP-12 expression in the tumor is associated with reduced survival, whereas Shah and colleagues ${ }^{5}$ detected similar MMP-12 expression levels in recurrent and nonrecurrent tumors. Thus, although there is sufficient evidence to conclude that MMP-12 is overexpressed in human lung cancer, the parenchymal source of MMP-12 in these tumors and the pro- or antineoplastic effects that MMP-12 may have on tumor progression remain an area of dispute.

Studies in murine lung-cancer models have yielded conflicting evidence regarding the effects of MMP-12 on tumor propagation. To illustrate, studies that tested the growth of tail vein-injected Lewis Lung carcinoma (LLC) cells in control and in MMP-12-deficient (MMP-12 knockout [KO]) mice demonstrated that LLC cells formed large and vascular tumors in the lungs of the MMP-12 KO mice but that they formed relatively smaller and avascular tumors in the lungs of control mice. It was proposed that increased MMP-12-driven generation of angiostatin in the control group was responsible for the delay in tumor growth. ${ }^{7,12}$ In stark contrast, when Qu and colleagues $^{13}$ used a bitransgenic MMP-12 overexpression modeling system to test the effects of MMP-12 on lung tumorigenesis, they found that discrete overexpression of MMP-12 in myeloid cells induced immune suppression and enhanced lung tumorigenesis. They further found that when MMP-12 was specifically overexpressed in lung epithelial cells, it promoted emphysema to lung adenocarcinoma transition. ${ }^{14}$ Taken together, on the one hand, these studies indicate an antiangiogenic role for MMP-12 in the lung microenvironment, and on the other hand, they propose that MMP-12 is directly protumorigenic. Thus, further research elucidating the role of MMP-12 in lung tumorigenesis is clearly warranted.

To more comprehensively dissect the role of MMP- 12 in lung tumorigenesis, we first characterize MMP-12 expression and correlation with survival in human lung cancer tissue samples and databases. ${ }^{15}$ Next, we test the distinct pro- and antitumorigenic roles of MMP-12 in a unique orthotopic model of the disease. We report that a diverse set of human lung cancers stained positive for MMP-12 and that high MMP-12 mRNA levels in NSCLC were associated with reduced survival. In addition, we show that MMP-12 is pivotal in promoting the invasion and growth of murine lung cancer cells both in vitro and in vivo. We conclude that in the context of lung tumors, tumor-derived MMP-12 is protumorigenic.

\section{MATERIALS AND METHODS \\ Cell Lines}

The human 460 lung cancer cell line (H460), large cell carcinoma, and murine LLC cell line were all purchased from the American Type Culture Collection. LLC green fluorescent protein (GFP) cells were generated in our laboratory as previously described. ${ }^{16} \mathrm{MMP}-12 \mathrm{KO}$ LLC cells were generated for this study as described next. All cell lines were maintained in Roswell Park Memorial Institute (RPMI) medium (BD Biosciences, San Jose, Calif) containing 10\% fetal calf serum (FCS), $1 \mathrm{mmol} / \mathrm{L} \mathrm{L-glutamine,} 100 \mathrm{U} / \mathrm{mL}$ penicillin, and $0.01 \mathrm{mg} / \mathrm{mL}$ streptomycin (Biological Industries, Kibbutz Beth Haemek, Israel). All cell lines were tested for mycoplasma contamination and found to be negative.

\section{Mice}

C57BL/6 (Harlan Laboratories Ltd, Indianapolis, Ind) and C57BL/ 6-MMP-12 KO (provided by Dr Dive, CEA Saclay, France) mice were used in the experiments.

\section{In Vivo Experimental Design}

In brief, cultured LLC or $\mathrm{H} 460$ cells $\left(1 * 10^{3}\right.$ per $\left.1 \mu \mathrm{L}\right)$ were harvested and suspended in RPMI-1640 (BD Biosciences). Before injection, the cells were mixed with Matrigel (BD Biosciences) at a 1:1 ratio and kept on ice until injection. For injection, the cell mixture was gently mixed and transferred into a $10-\mu \mathrm{L}$ syringe (Hamilton, Reno, Nev) fitted with a 


\begin{tabular}{|c|c|c|c|c|c|c|}
\hline Gene & Tissue & minimum & Q1 & Median & Q3 & P value \\
\hline MMP-12 & Normal & 2 & 49 & 97 & 3392 & \\
\hline MMP-12 & Cancer & 2 & 464 & 1792 & 35159 & $\mathrm{P}<0.0001$ \\
\hline
\end{tabular}
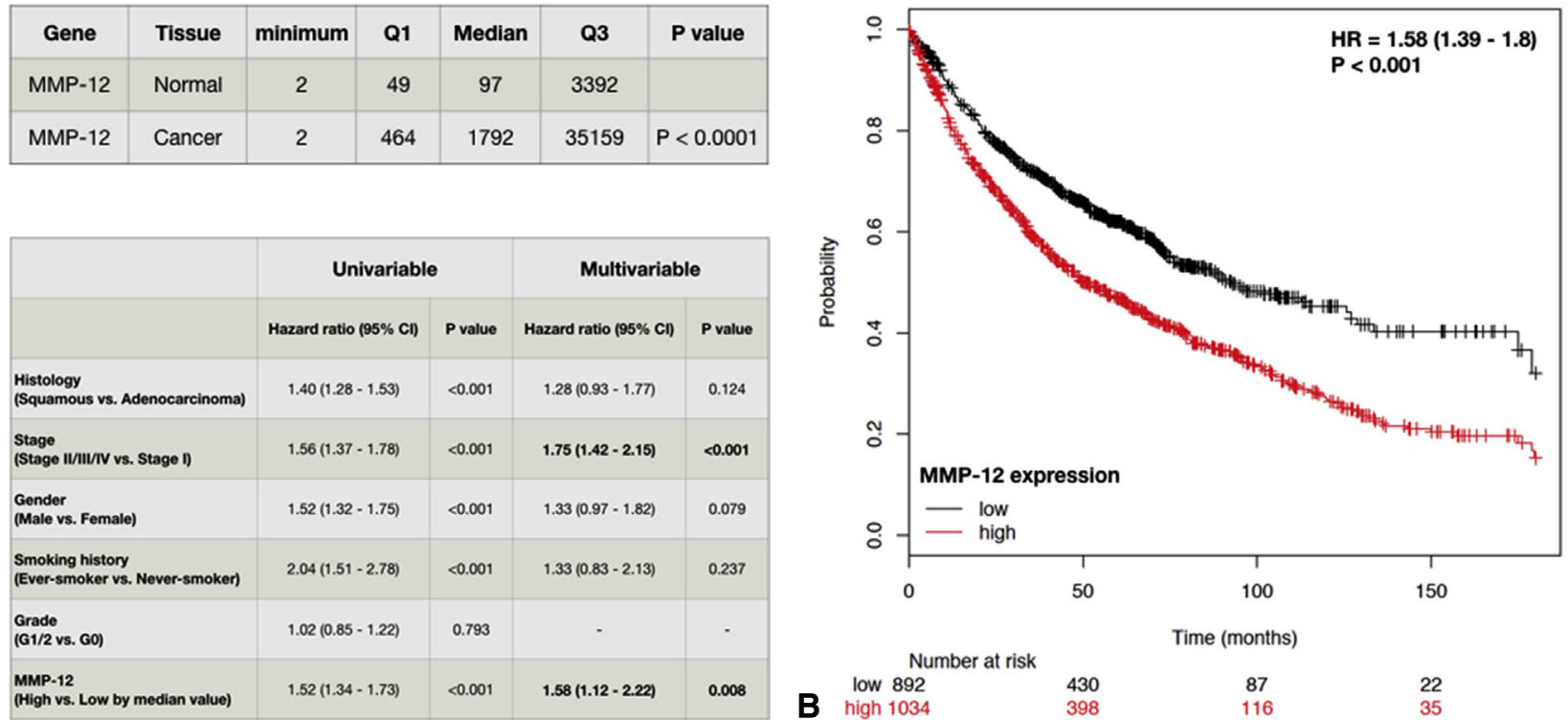

high 1034

398

116

FIGURE 1. MMP-12 mRNA expression and correlation with survival in published lung cancer databases. A, The table shows the minimum, first quartile, median, third quartile, and maximal values of MMP-12 probe detection in normal lung and in lung cancer samples. B, Kaplan-Meier Plot shows the longterm overall survival of patients with lung cancer expressing low and high MMP-12 mRNA levels in their tumors. C, The table shows the HR and the $P$ value for the univariable and multivariable analyses to evaluate the significance of MMP-12 gene in NSCLC overall survival. In the univariable analysis, the HPRT1 gene was used as a reference gene (see "Materials and Methods" section). MMP-12, Matrix metalloproteinase 12; $H R$, hazard ratio; $C I$, confidence interval.

31-gauge needle. The syringe was loaded on the stereotactic injection system, and $2 \mu \mathrm{L}$ of cell mixture was injected directly into the left lung of each mouse. For more details regarding tumor inoculation, see the work by Weiss and colleagues. ${ }^{16}$

Lung harvesting was performed 3 weeks after tumor inoculation. First, mice were euthanized by overdose injection of Ketamine/Xylazine. Next, the chest cavity was exposed and the lungs were perfused with $4 \%$ buffered paraformaldehyde or normal saline via the trachea. Then, the lungs were harvested.

We have previously reported that in the model applied in this study, LLC cells growing in vivo for 3 weeks do not form metastasis and that keeping the mice alive for a longer time period is impossible because of severe symptoms related to the growth of the primary tumor. Therefore, in the current work, we have not tested for lymph node or distant metastasis. ${ }^{16}$

For each cell line (LLC and MMP-12 KO LLC), 10 mice were inoculated with tumor $(\mathrm{n}=10$, total of 20 mice in experiment). The animal care and use committee at Hadassah University Hospital approved the experimental protocol used in this study (MD-15-14384-4).

\section{Histology, Hematoxylin-Eosin, Immunohistochemistry Staining, and Determination of Tumor Size}

Human lung cancer tissue array was purchased from US Biomax, Inc (Rockville, Md) (sample number BC041115as). For MMP-12 immunohistochemistry, we used the Abcam (Cambridge, United Kingdom) ab52897 anti-MMP-12 antibody as described next. An independent lung pathologist (GA) blindly evaluated MMP-12 staining intensity in the lung tissue array. The percentage of cells staining positive for MMP- 12 was evaluated as $0 \%$ to $25 \%, 26 \%$ to $50 \%, 51 \%$ to $75 \%$, and $76 \%$ to $100 \%$. The staining strength was graded on a scale of 0 to 3 , with 0 indicating no staining and 3 indicating strong staining. Tumor qualifying for the high staining intensity definition had more than $50 \%$ of cells staining in strength of 2 or 3 .

Murine tissue samples of control lungs and tumor-bearing lungs were routinely fixed with formalin and embedded in paraffin. Tissues were then serially sectioned in 4 - to $7 \mu \mathrm{mol} / \mathrm{L}$ thickness and transferred to slides for staining. For immunohistochemistry, slides were incubated with anti-MMP-12 (Abcam ab52897) or anti-GFP (Santa Cruz Biotechnology, Inc, Dallas, Tex; SC-8334 and SC-9996). 3-Amino-9-ethylcarbazole was used for color development, and sections were counterstained with hematoxylin. Elastin staining was performed according to a standard Verhoeff-Van Gieson staining protocol.

To determine the tumor volume, the maximal tumor diameter was first defined by reviewing stained serial sections from the center of the tumor. Next, for each tumor ( $\mathrm{n}=10$ per cell line), the maximal diameter was divided by 2 to generate the tumor radius (r), and the $4 / 3 \pi \mathrm{r} 3$ equation was used to calculate the volume. The $t$ test was used to compare between the 2 groups.

\section{Human Overall Survival Correlation Analysis}

Univariable analysis. We analyzed the association of MMP-12 mRNA expression with overall survival of patients with lung cancer through an online tool (www.kmplot.com) ${ }^{15}$ suitable for the real-time meta-analysis of published lung cancer microarray datasets from the caBIG, GEO, and TCGA repositories. Overall survival in this scenario is calculated on the basis of the input from each of the datasets in the database. More specifically, it is calculated as survival from the date of diagnosis in nonsurgically treated patients with lung cancer and as survival from the date of surgery in surgically treated patients. Therefore, the overall survival data should be somewhat cautiously interpreted. For alive patients, censoring occurs on the date of last confirmed alive follow-up. For the current study, analysis of 1926 samples derived from independent datasets were integrated into the system to permit for overall survival analysis. On the basis of our query, the system has generated a Kaplan-Meier survival plot and calculated the hazard ratio (HR) and log rank $P$ value for the MMP-12 probe - 204580_at (the single MMP-12 probe that is available). To assess the prognostic value of the MMP-12 gene, the Kaplan-Meier survival plot tool computed each percentile (of expression) between the lower and upper quartiles, and the best performing threshold was used as the final cutoff in a univariable Cox regression analysis. 
Multivariate analysis. The Kaplan-Meier survival plot tool offers the option to perform a multivariable analysis including the selected gene (MMP-12 in this article) and additional clinical parameters, such as histology, stage, gender, grade, and smoking history. However, it does not provide access to the original data of each of the datasets integrated into the database. Therefore, the Kaplan-Meier survival plot tool limits the option of generating values for the univariable parameters that may be included in the multivariable analysis (histology, stage, gender, grade, and smoking history). To overcome this limitation, we have confirmed in the database that hypoxanthine phosphoribosyltransferase 1 [HPRT1]; 202854_at) and Esterase D 209009_at), known as reference genes for gene expression on NSCLC, ${ }^{17}$ did not show any statistical differences in overall survival (HPRT1 $P=.43$; HR, 1.05; 0.93-1.15) and Esterase D $P=.62$; HR, 0.97; 0.85-1.10, respectively). A univariable analysis of each variable considering HPRT1 to be a reference gene was performed. Variables with a $P$ value less than .01 in univariable analysis were considered as candidate variables for multivariable analysis (Figure 1, C). We did not use the Kaplan-Meier survival plot tool exclusion option to exclude any patients from the analysis, because this would have significantly lowered the number of samples analyzed.

The publication describing the construction of the database provides some information with respect to the clinical characteristics of the patients included in each of the datasets that compose it. In particular, the median overall survival follow-up in the various datasets ranged from 5.4 to 58.2 months; the average age of patients ranged from $60 \pm 8.1$ years to $67 \pm 9.8$ years; the histology included adenocarcinoma, squamous cell carcinoma, and large cell carcinoma; and patients with stage 1 to 4 were included, with the majority being in stage 1 and 2. For more information about the Kaplan-Meier survival plot tool, we refer the readers to the website and to Gyorffy and colleagues. ${ }^{15}$

\section{Quantitative Polymerase Chain Reaction Analysis}

Quantitative polymerase chain reaction (PCR) analysis of the expression of MMP-12 was performed using PerfeCTa SYBR Green (Quantabio, Beverly, Mass). MMP-12-specific primers were designed by Affymetrix matched oligos on expression chip. The experiment was performed according to the manufacturer's instructions. HPRT gene was used as housekeeping gene. For RNA extraction, we used 3 samples of LLC cells growing in culture $(\mathrm{n}=3), 4$ LLC cell-derived tumors growing in C57BL/6 mice $(\mathrm{n}=4)$, and 4 LLC cell-derived tumors growing in C57BL/6-MMP-12 KO mice $(\mathrm{N}=4)$. For each of these samples, quantitative PCR was performed in triplicate.

\section{Lung Extract Preparation}

Lung extract was prepared by homogenizing the entire perfused lung tissue from $1 \mathrm{MMP}-12 \mathrm{KO}$ or control mouse in $4 \mathrm{~mL}$ of RPMI. Next, the suspension was centrifuged and filtered via a $70-\mu \mathrm{m}$ pore mash to remove any remaining cell debris. The filtered supernatant was used as lung extract.

\section{Enzyme-Linked Immunosorbent Assay}

LLC-derived lung tumors $(\mathrm{n}=5)$ and control normal lung tissue samples $(\mathrm{n}=3)$ were homogenized in Greenberger Lysis Buffer containing $300 \mathrm{mmol} / \mathrm{L} \mathrm{NaCl}, 15 \mathrm{mmol} / \mathrm{L}$ Tris, $2 \mathrm{mmol} / \mathrm{L} \mathrm{MgCl}$, $2 \mathrm{mmol} / \mathrm{L}$ Triton (X-100), and protease inhibitors (Complete Mini Roche diagnostic GmbH, Mannheim, Germany, Ref 11836153001) 1 tablet per $10 \mathrm{~mL}$. One milligram of tissue was homogenized in $20 \mu \mathrm{L}$ lysis buffer. After homogenization, the suspension was centrifuged and MMP-12 levels were determined in the supernatant by enzyme-linked immunosorbent assay (ELISA) according to the manufacturer's instructions (MMP-12 Elisa kit - EA100640; OriGene Technologies, Rockville, Md). For each of the samples (5 tumor and 3 normal lung), the ELISA was done in duplicates. Protein content in each tissue sample was determined by Bradford assay, and MMP-12 content in each sample was then calculated relative to the protein content in the sample to yield picogram MMP-12/mg total protein scale. The $t$ test was used to compare between the tumor and lung samples.
MMP-12 production by LLC and LLC-MMP-12-KO cells growing in culture in the presence or absence of lung tissue extract was determined as follows. First, the cells were grown in 24 -well plates until $70 \%$ confluent. Next, the cell culture medium was removed and the lung extract (derived from the perfused lungs of MMP-12 KO mice) was added for 24 hours. Subsequently, the supernatant was collected and analyzed by ELISA for MMP-12 $(\mathrm{n}=3$ per each cell line).

\section{Cell Proliferation Assay}

A total of 65,000 LLC cells and MMP-12 knock6out LLC cells were seeded separately in 6-well plates, 4 plates per cell line in their proper media ( $10 \% \mathrm{FCS}$ ), and incubated in $37^{\circ} \mathrm{C}$. After 48 hours, cells were visualized to detect their confluence state. One plate (containing 6 repetition [wells] for each time point) was taken for cell viability detection at days 2, 3, 4, and 5. To determine cell viability, WST-8 reagent was added to each well and cells were incubated in $37^{\circ} \mathrm{C}$ for 1 hour. Absorbance was measured at $450 \mathrm{~nm}$ using a plate reader (Wallac 1420 VICTOR plate-reader, Perkin-Elmer Life Sciences, Akron, Ohio).

\section{Colony Assay}

To study the different potential of LLC cells and MMP-12 KO LLC cells to form colonies, soft agar assay was performed. Each well of a 6-well culture plate was coated with $2 \mathrm{~mL}$ bottom agar mixture (RPMI, $10 \%$ FCS, $2 \%$ agar). After the bottom layer had solidified, $1 \mathrm{~mL}$ top agar mixture (RPMI, $10 \%$ FCS, $0.6 \%$ agar) containing 10,000 cells per well was added. After this layer had solidified, wells were overlaid with an additional $1 \mathrm{~mL}$ of RPMI, $10 \%$ FCS. Plates were incubated at $37^{\circ} \mathrm{C}$, and the medium was refreshed every 2 days. On day 8 , colonies were visualized using a light microscope, and colonies from different fields of view ( 4 fields per well) were counted under $\times 10$ magnification. The average number of colonies per well was calculated ( 4 wells per each cell line, a total of 16 separates counts for each cell line). The $t$ test was used to compare between the 2 cell lines.

\section{Polymerase Chain Reaction and Primer List}

PCR primers were used as follows:

Uni primers were used to detect both bands of DNA and RNA in the same assay: 607 and 211 base pairs, respectively.

DNA primer was used to detect DNA sequences only.

J primers were used to detect RNA sequences only (in exon-intron junctions).

We used 2 different primer pairs to identify Puromycin insertion by PCR.

\begin{tabular}{llcc}
\hline & & \multicolumn{2}{c}{ Product } \\
Primer name & \multicolumn{1}{c}{ Sequence } & PCR & size \\
\hline MMP12-Funi & GGCTGCAGCATTCCAATAAT & DNA/ & $607 / 211$ \\
& & RNA \\
MMP12-Runi & CCCACTGTTGTGACAGCATC & DNA/ & $607 / 211$ \\
& & RNA \\
MMP12-Rdna & CATGTGTGTGTGGCATTGAA & DNA & 156 \\
MMP12-Rj & CATTTGGAGCTCACGGAGAC & RNA & 315 \\
MMP12-Rj & CACTGGGGCTCCATAGAGGGAC & RNA & 315 \\
Puro1-F & ACAGATGGAAGGCCTCCTG & DNA & 196 \\
Puro1-R & CTCGTAGAAGGGGAGGTTGC & DNA & 196 \\
Puro2-F & GTCACCGAGCTGCAAGAACT & DNA & 204 \\
Puro2-R & CAGGAGGCCTTCCATCTGT & DNA & 204 \\
HPRT-F & GTTAAGCAGTACAGCCCCAAA & RNA & 215 \\
HPRT-R & AGGGCATATCCAACAACAAACTT & RNA & 215 \\
\hline
\end{tabular}



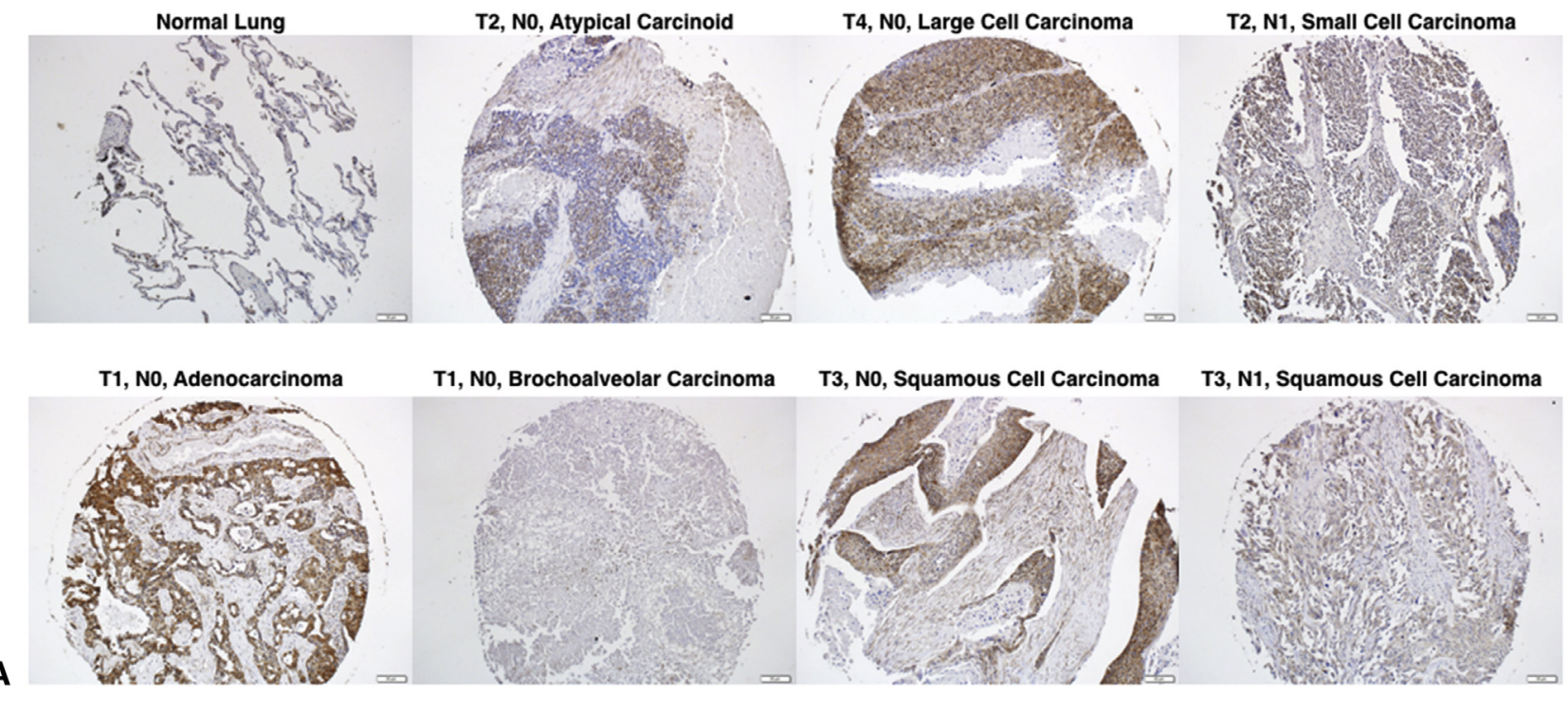

T3, N1, Squamous Cell Carcinoma

\begin{tabular}{|c|c|c|c|c|c|c|}
\hline & $\begin{array}{c}\text { Squamous Cell } \\
\text { Carcinoma }\end{array}$ & Adenocarcinoma & $\begin{array}{c}\text { Bronchoalveolar } \\
\text { Carcinoma }\end{array}$ & $\begin{array}{c}\text { Atypical } \\
\text { Carcinoid }\end{array}$ & $\begin{array}{c}\text { Large Cell } \\
\text { Carcinoma }\end{array}$ & $\begin{array}{c}\text { Small Cell } \\
\text { Carcinoma }\end{array}$ \\
\hline $\begin{array}{c}\text { MMP-12 High } \\
\text { Staining } \\
\text { Intensity }\end{array}$ & $22 / 43(51 \%)$ & $22 / 38(58 \%)$ & $0 / 4(0 \%)$ & $3 / 4(75 \%)$ & $2 / 4(50 \%)$ & $6 / 6(100 \%)$ \\
\hline
\end{tabular}

FIGURE 2. MMP-12 expression in human lung cancers. A, Representative staining for MMP-12 in normal lung and in primary malignant tumors of the lung. B, For each histologic subtype, the table shows the number and percentage of tumors staining with high intensity for MMP-12. MMP-12, Matrix metalloproteinase 12 .

\section{Generation of Matrix Metalloproteinase 12 Knockout Lewis Lung Carcinoma Cells (Murine) Cells}

An MMP-12 KO cell line was generated from the parental LLC cell line using clustered regularly interspaced short palindromic repeats in a $\mathrm{KO}$ system (Santa Cruz Biotechnology, Inc). By transfecting MMP-12, clustered regularly interspaced short palindromic repeats/Cas9 KO Plasmid (m) sc-421667 and the HDR plasmid SC-421667-HDR using Lipofectamine (Thermo Fisher Scientific, Waltham, Mass) and according to the manufacturer's instructions.

\section{RESULTS}

\section{Tumor Cells of All Major Subtypes of Human Lung Cancer Stain Positive for Matrix Metalloproteinase} 12

To test the expression and tissue localization of MMP-12 in primary lung tumors, we stained a human lung cancer tissue array for MMP-12. We found that in the normal lung, cells with alveolar macrophage morphology weakly stained for MMP-12 and that bronchial and alveolar epithelial cells nearly did not stain for MMP-12. In contrast, we detected staining for MMP-12 in tumor cells of all major lung cancer subtypes (Figure 2, A). In particular, high-intensity staining for MMP-12 was found in $51 \%$ (22/43) of squamous cell carcinomas, in 58\% (22/38) of adenocarcinomas, and in $78 \%(11 / 14)$ of neuroendocrine tumors $(75 \%$ [3/4] of atypical carcinoids, $50 \%$ [2/4] of large cell carcinomas, and $100 \%$ [6/6] of small cell carcinomas) (Figure 2, B). Tumors categorized in this array as bronchoalveolar carcinomas showed only weak or negative staining for MMP-12, and none of the samples $0 \%(0 / 4)$ were categorized as having high-intensity MMP-12 staining. Viewed as a whole, these results demonstrate that MMP-12 is often highly produced by epithelial cells of a diverse set of lung malignancies.

\section{High Matrix Metalloproteinase 12 mRNA Expression Is Associated With Reduced Survival in Patients With Lung Cancer}

We used the web-based Kaplan-Meier Plotter software (www.kmplot.com) both to compare the expression levels of MMP-12 mRNA in normal lung with those in lung cancer and to correlate between MMP-12 mRNA expression levels and the overall survival of 1926 patients with lung cancer, of whom $967(50.2 \%)$ died during follow-up. ${ }^{15}$ In line with the immunohistochemical staining described, we found that the signal for the MMP-12 probe 204580_at was significantly elevated in lung cancers compared with normal lung parenchyma $(P<.0001$, probe detection range in lung cancer: 2-35,159, median $=1792$ and in normal lung: 2-3932, median =97) (Figure 1, A). Furthermore, as shown in Figure $1, B$, we found that the survival of patients who 


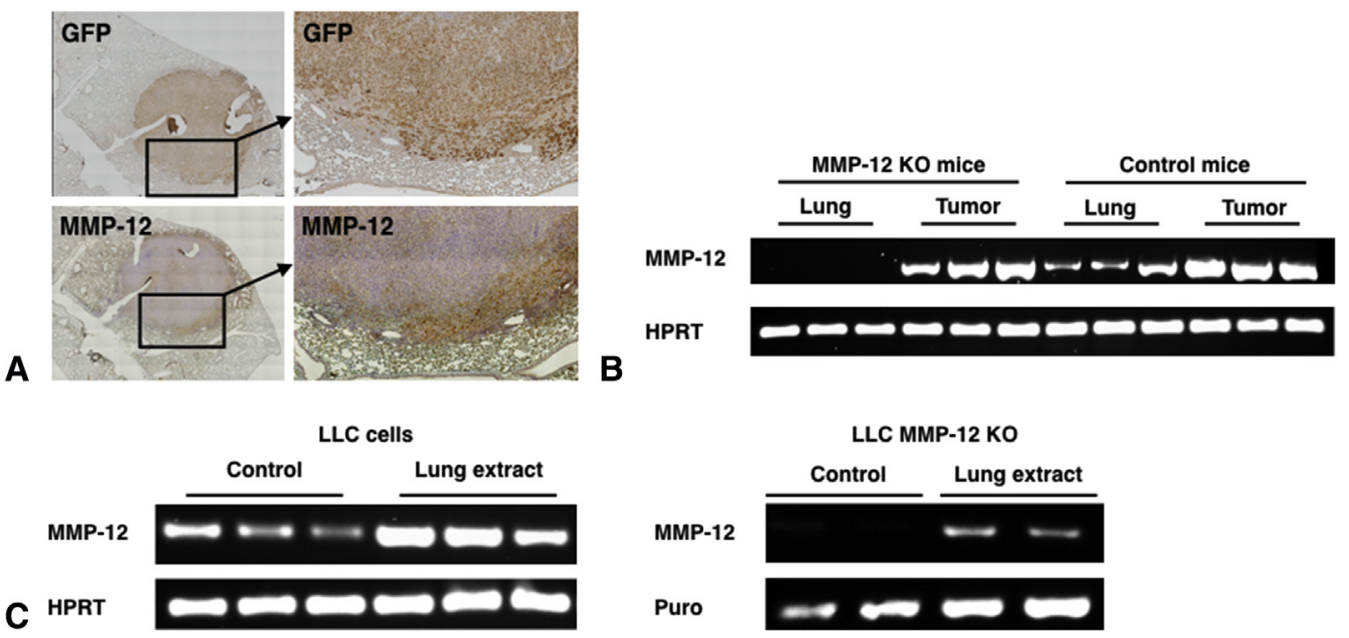

FIGURE 3. MMP-12 expression in vivo, in tumors induced in control and in MMP-12 KO mice, and in vitro, in LLC and LLC MMP-12 KO cells stimulated with lung extract. A, Serial sections of a tumor induced by the injection of LLC-GFP cells to the murine left lung. Top: low and high magnification of staining for GFP. Bottom: low and high magnification of staining for MMP-12. B, Reverse transcriptase PCR for MMP-12 and HPRT on the lungs of control and MMP-12 KO mice and on LLC tumors removed from the lungs of control and MMP-12 KO mice. C, Reverse transcriptase PCR for MMP-12, HPRT, and Puromycin on LLC and LLC MMP-12 KO cells growing in culture in the presence or absence of lung extract. GFP, Green fluorescent protein; $M M P$-12, matrix metalloproteinase 12; KO, knockout; HPRT, hypoxanthine phosphoribosyltransferase; $L L C$, Lewis lung carcinoma.

had high MMP-12 expression in their tumor (probe detection rate cutoff $=1540$ ) was significantly shorter (median survival of 50 months) compared with that of patients with low MMP-12 expression in their tumors (median survival of 92.6 months) (log-rank $P<.001$; HR, 1.58; 1.39-1.8). In addition, a multivariable analysis that we performed with the Kaplan-Meier survival plot tool (and that included the parameters tumor histology, disease stage, gender, smoking history, and MMP-12 gene) suggested that MMP-12 is as an independent risk factor for reduced survival (MMP-12 HR, 1.58; 1.12-2.22; $P=.008$ ) (Figure $1, C$ ). As a whole, these observations suggest that high MMP-12 mRNA expression in NSCLC tumors is associated with reduced patient survival.

\section{Lewis Lung Carcinoma-Derived Orthotopic Lung Tumors Express Matrix Metalloproteinase 12 in a Manner Similar to Human Lung Cancers}

We have previously reported that injection of minute numbers of lung cancer cells directly to the murine left lung generates a single pulmonary nodule that is surrounded by normal lung parenchyma and that propagates in an intact lung microenvironment. ${ }^{16} \mathrm{We}$ consider this modeling system to recapitulate multiple characteristics of early-stage human lung cancer. A preliminary set of unpublished genetic experiments that we have conducted suggested that MMP-12 is highly expressed in such orthotopically derived tumors. To validate these observations in the current study, we first stained serial sections of tumors generated from LLC-GFP cells for GFP and MMP-12. As shown in
Figure 3, A, tumor cells (identified by positive GFP staining) in the periphery of the tumor strongly stained for MMP-12 (Figure 3, A). Low levels of MMP-12 staining were also detected in tumor surrounding inflammatory cells. To further validate these observations, tumor samples were homogenized and ELISA assays were performed. We found a more than 20-fold increase in MMP-12 protein content in the tumors compared with the normal lung parenchyma $(P<.001$, MMP-12 $\mathrm{pg} / \mathrm{mg}$ protein in tumors $=23,417 \pm 2426$ vs MMP-12 $\mathrm{pg} / \mathrm{mg}$ protein in normal lung parenchyma $=476 \pm 30$ ). To test the robustness of the results and to ensure that MMP-12 expression in the tumor was not restricted to a specific mouse strain or cell line, we used the H460 lung cancer cell line to induce orthotopic tumors in NSG mice. Next, we stained the tumors for MMP-12 and evaluated MMP-12 transcript levels in the tumor and lung by PCR. Similar to the results obtained with the LLC-GFP cells, we detected strong staining for MMP-12 in the periphery of H460-derived tumors; these results were further supported by the PCR results (Figure E1, $A$ and $B$ ). These findings suggest that orthotopically induced LLC tumors produce MMP-12 and that in these tumors the tumor cells in the tumor's periphery highly express MMP-12.

\section{Lung Microenvironment Stimulates Lewis Lung Carcinoma Cells (Murine) Cells to Produce Matrix Metalloproteinase 12}

To further confirm that LLC cells are an important source of MMP-12 production in vivo, these cells were implanted in the lungs of control and MMP-12 KO mice, and tumors 
were then harvested for analysis. As shown in Figure 3, B, MMP-12 mRNA was detected in tumors but not in the lungs obtained from MMP-12 KO mice, whereas it was detected both in tumors and in lungs obtained from control mice. To validate these observations and compare the relative MMP-12 mRNA expression in LLC cells growing in vitro with those in LLC cells growing in vivo, we next performed quantitative PCR for MMP-12 (on LLC cells growing in culture and on LLC and MMP-12 KO LLC cells growing in vivo). We found a 6- to 7-fold increase in MMP-12 transcript levels in LLC tumor samples (growing both in control and in MMP-12 KO mice) compared with LLC cells growing in culture (data not shown). Thus, we propose that on implantation in the lung, LLC cells upregulate MMP-12 expression. To recapitulate these observations in vitro, we next stimulated LLC cells with lung extract (derived from the lungs of MMP-12 KO mice). We found that in response to this treatment, LLC cells upregulated MMP-12 mRNA expression (Figure 3, C) and protein production (MMP-12 protein in media of control LLC cells $218 \pm 3 \mathrm{pg} / \mathrm{mL}$ vs $1693 \pm 3 \mathrm{pg} / \mathrm{mL}$ in media of stimulated LLC cells). In addition, we have generated a LLC MMP-12 KO cell line and were able confirm that compared with LLC cells, MMP-12 mRNA expression (Figure 3,C) and protein production in the MMP-12 KO cell line were dramatically reduced both at baseline and after stimulation with lung extract (MMP-12 protein in media of LLC MMP-12 KO cells, not detected, vs $249 \pm 7 \mathrm{pg} / \mathrm{mL}$ in media of stimulated LLC MMP-12 KO cells). These observations indicate that the lung microenvironment stimulates MMP-12 production by cancerous cells both in vivo and in vitro.

Knockdown of MMP-12 in LLC cells does not affect their proliferation rate but does reduce their colony-forming capacity in vitro and their growth in vivo. To evaluate the effects of knockdown of MMP-12 on the tumorigenicity of LLC cells, we first tested in vitro the proliferation and the agar colony-forming capacity (an indicator of invasiveness) of LLC and MMP-12 KO LLC cells. As shown in Figure 4, A, MMP-12 KO LLC cells proliferated slightly more rapidly than their parental LLC cells and reached peak proliferation at day 4 rather than day 5 after plating. Nonetheless, we found that LLC cells, rather than MMP-12 KO LLC cells, were significantly more efficient in their colony formation capacity $(P<.001)$ (Figure $4, B)$. We next compared the growth of LLC and MMP-12 KO LLC cells in vivo. As shown in Figure 4, $C$ and $D$, LLC cells formed significantly $(P<.01)$ larger tumors compared with the MMP-12 KO LLC cells. When LLC cells were implanted in control mice and in MMP-12 KO mice, there was no significant difference in tumor size (data not shown). Thus, we suggest that tumor-derived rather than host-derived MMP-12
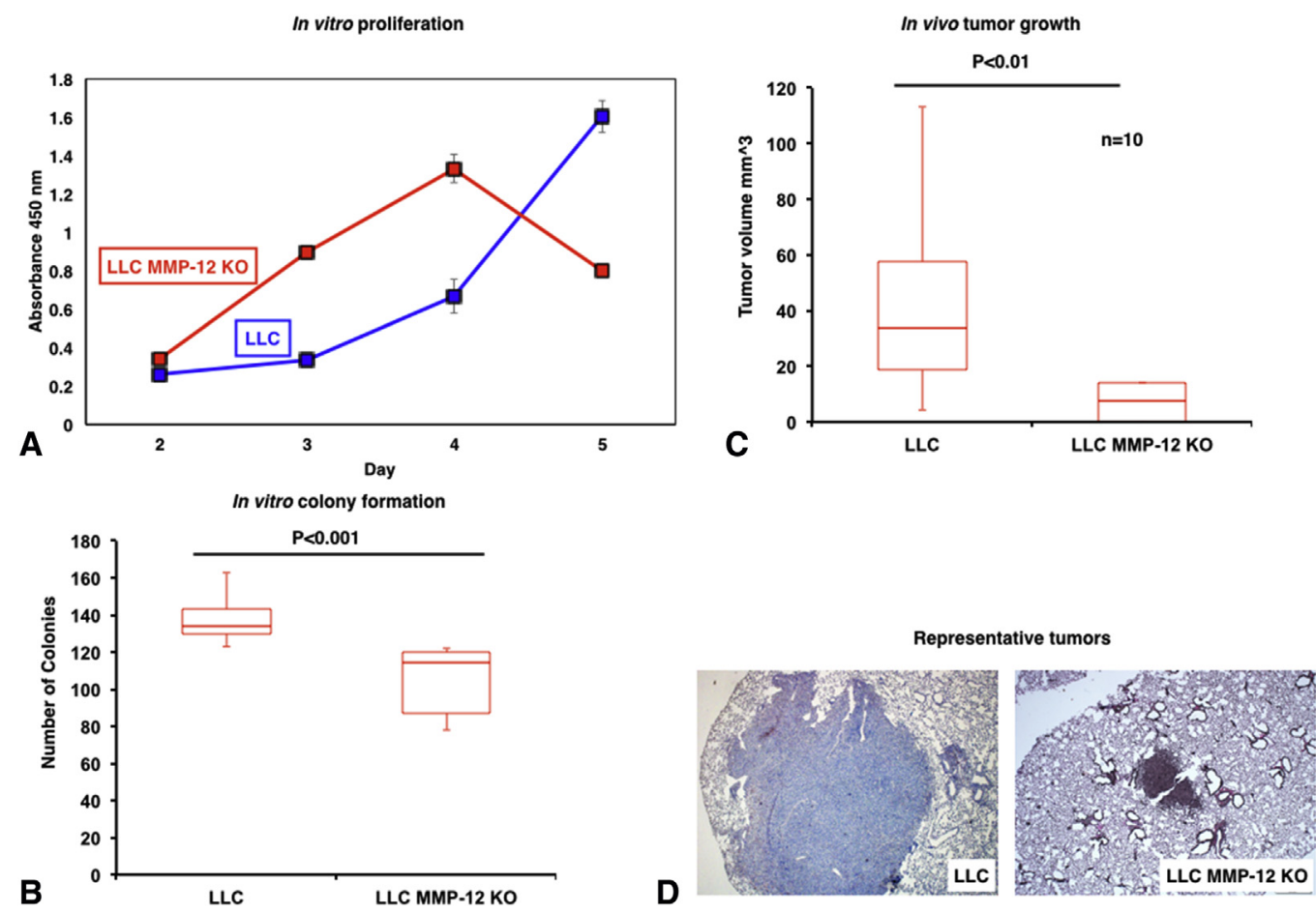

FIGURE 4. In vitro proliferation, colony forming capacity, and in vivo growth of LLC and LLC MMP-12 KO cells. A, In vitro proliferation of LLC and LLC MMP-12 KO cells. B, The colony forming capacity of LLC and LLC MMP-12 KO cells. C, The tumor volume of tumors derived from the injection of LLC and LLC MMP-12 KO cells to the lungs of C57B1/6 mice. D, Representative low-power magnifications of LLC and LLC MMP-12 KO tumors. $L L C$, Lewis lung carcinoma; $M M P-12$, matrix metalloproteinase $12 ; K O$, knockout. 

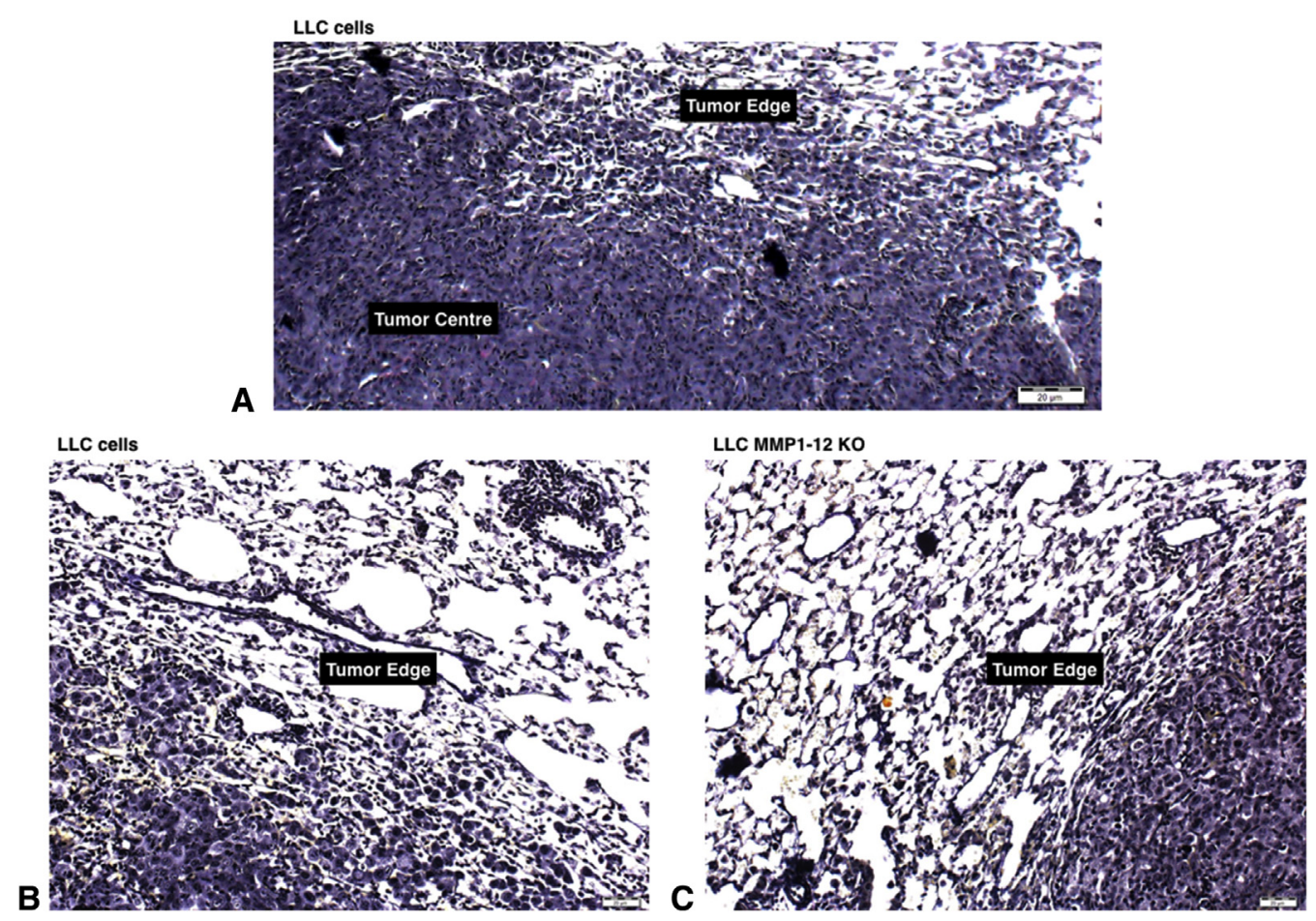

FIGURE 5. Elastin staining in LLC and LLC MMP-12 KO tumors. A, Representative staining of an LLC-derived tumor for elastin is shown. Image was taken to demonstrate tumor edge and more central parts of the tumor. B, The edge of an LLC-derived tumor. C, The edge of an LLC MMP-12 KO-derived tumor. $L L C$, Lewis lung carcinoma; $M M P-12$, matrix metalloproteinase 12; KO, knockout.

promotes tumor growth in the lung. Finally, we stained tumor sections derived from LLC and MMP-12 KO LLC cells for elastin and specifically evaluated the tumor morphology and elastin staining at the tumor edge. As illustrated in Figure 5, $A$ to $C$, elastin was degraded at the edge of both the LLC and MMP-12 KO LLC-derived tumors. Furthermore, the content of elastin was declining toward the center of the tumor, and nearly no elastin fibers were detected in the tumor center (Figure 5, A). When evaluating the morphology of the tumor edge, our impression was that the edge of the LLC tumors was irregular with multiple tumor cells skipping/invading to neighboring alveoli (Figure 5, $A$ and $B$ ), whereas the edge of the LLC MMP-12 KO tumors was relatively smoother and more regular (Figure 5, C).

\section{DISCUSSION}

In this study, we sought to thoroughly investigate the role of MMP-12 in tumor propagation in the lung. We report that a variety of human lung cancer cells stained positively for MMP-12 (Figure 2) and that the high expression of MMP-12 mRNA in the tumor was associated with reduced survival (Figure 1). In addition, we report that lung cancer cells produced low baseline levels of MMP-12 and that on exposure to lung tissue extract (Figure 3) or implantation in the lung, these cells upregulated MMP-12. Moreover, we demonstrate that in vitro, the invasiveness of
MMP-12-deficient cells was reduced compared with that of MMP-12-producing cells and that in vivo, MMP-12-deficient cells generated smaller tumors (Figure 4). Taken together, these findings strongly suggest that tumor-derived MMP-12 promotes tumor propagation in the lung.

Our experiments and observations advance the current knowledge regarding the role of MMP-12 in lung tumorigenesis in the following ways:

First, our MMP-12 immunohistochemical staining extend the observations made by Hofmann and colleagues ${ }^{9}$ and Acuff and colleagues ${ }^{7}$ regarding the expression of MMP-12 in NSCLC by showing, for the first time, that other primary tumor of the lungs (in particular atypical carcinoids and small cell lung cancers) also highly express MMP-12. The 4 samples of "bronchoalveolar carcinomas" in our array did not stain positive for MMP-12, thereby potentially indicating that MMP-12 is not as frequently expressed in these less-aggressive tumors. In addition, by showing that in the majority of the tumors we stained, high staining for MMP-12 was mainly detected in tumor cells and not in tumor-infiltrating immune cells, we help solve the controversy regarding the predominant cellular source of MMP-12 in the tumors.

Second, by interpreting data derived from 1926 cases, we are able to provide a more robust analysis of the positive association between the expression levels of MMP-12 and 


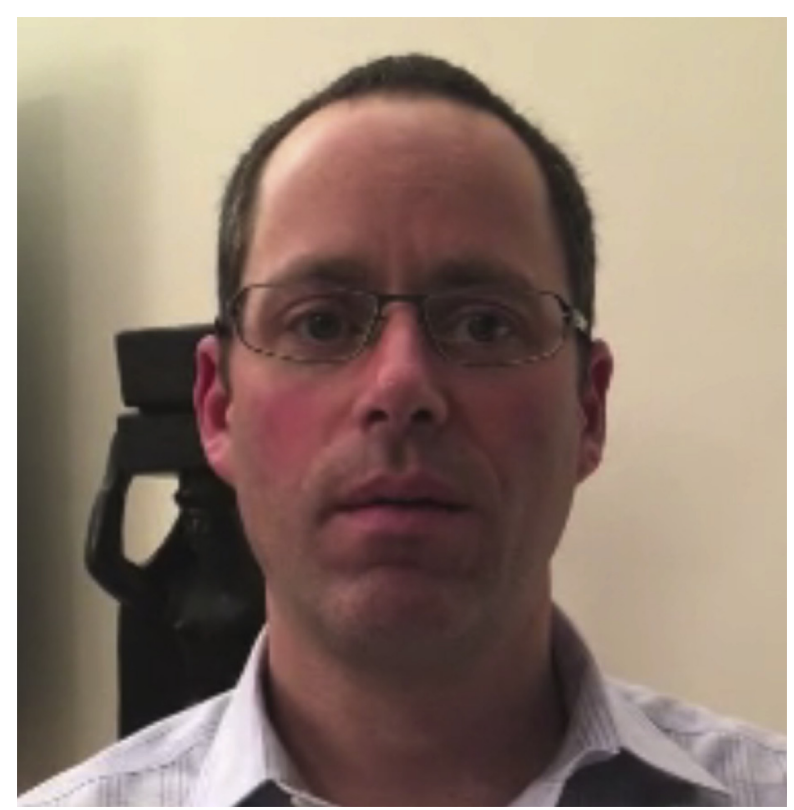

VIDEO 1. The video presents the key findings of our study. Video available at: http://www.jtcvsonline.org/article/S0022-5223(18)30069-2/ fulltext.

the survival of patients with NSCLC. This contrasts with previous reports that based their analysis on a small number of patients: 89 patients in the study of Hofmann and colleagues, ${ }^{9} 52$ patients in the study of Lv and colleagues, ${ }^{11}$ and 20 patients in the study of Cho and colleagues. ${ }^{10} \mathrm{We}$ show that high expression of MMP-12 in the tumor is associated with reduced survival and that in a multivariable analysis MMP-12 emerges as an independent risk factor for reduced survival (Figure E1).

Third, prior reports have indicated that various proteins and mechanical forces (including the calcium-binding protein S100A8/A9, the heterogeneous nuclear ribonucleoprotein $\mathrm{K}$, the T-box transcription factor brachyury, and fluid shear forces, measured by dyn $/ \mathrm{cm}^{2}$ units) induce endogenous upregulation of MMP-12 in malignant cells and that this in turn may enhance their malignant properties including their invasiveness. ${ }^{18-21}$ Yet, these reports mainly based their conclusions on in vitro studies. Moreover, in the few studies that did use in vivo modeling, MMP-12 was not endogenously induced in the malignant cells but rather genetically overexpressed. ${ }^{14,18-21}$ In contrast to this past research, we tested our hypothesis using an in vivo model that inherently induces the endogenous upregulation of MMP-12 in the tumor cells, and we specifically inhibited this process by silencing of MMP-12 in these cells. Consequently, we provide a more true-tolife evaluation of the role of MMP-12 in lung tumor propagation. In particular, we show that LLC cells endogenously upregulate MMP-12 in vitro on exposure to lung extract and in vivo at the tumor edge where they interact with the normal lung parenchyma. Further, we present for the first time in vivo-based experimental evidence indicating that lung microenvironment-dependent induction of MMP-12 in tumor cells is a protumorigenic process. Woenckhaus and colleagues $^{22}$ reported that MMP-12 is among the 5 genes that are constantly upregulated in bronchial epithelium isolated from smokers with premalignant central airway lesions. Our observations dovetail with this report and support the hypothesis that if induced in bronchial epithelium, MMP12 may indeed drive lung cancer propagation.

Fourth, in the current work, we tested the role of MMP-12 in lung tumorigenesis using experimental settings that accurately recapitulate the characteristics of early-stage human lung cancer. This contrasts sharply with the work of $\mathrm{Qu}$ and colleagues ${ }^{14}$ and Houghton and colleagues, ${ }^{12}$ who also tested the effects of MMP-12 on lung tumorigenesis but relied on models that do not properly mimic the disease. More specifically, $\mathrm{Qu}$ and colleagues ${ }^{14}$ overexpressed MMP-12 in the entire lung respiratory epithelium and found that increased production of MMP- 12 fostered tumor growth. Houghton and colleagues ${ }^{12}$ injected LLC cells in the tail vein of control and MMP-12 KO mice and found that metastatic LLC nodules do not produce MMP-12 and that production of MMP-12 by immune cells in the lung suppresses metastatic growth. We submit that our experimental methodology may help clarify the contradictory findings and dissipate the uncertainties presented in these studies. In particular, we propose that by monitoring the propagation of a solitary pulmonary nodule in an intact lung microenvironment, our observations extend the observations of $\mathrm{Qu}$ and colleagues ${ }^{14}$ by showing for the first time that specific and localized expression of MMP-12 by tumor cells (and not by the entire lung respiratory epithelium) is sufficient to promote tumor growth and invasiveness. We suggest that by reporting that LLC cells form tumors of similar size with comparable MMP-12 mRNA levels in control and in MMP-12 KO mice, we provide ample evidence to conclude that once induced in tumor cells, the protumorigenic effects of MMP12 may predominate over the antitumorigenic effects that immune-derived MMP-12 may exert. ${ }^{12}$ This assumption meshes nicely with previous reports by Kerkela and colleagues $^{23,24}$ showing that in squamous cell carcinoma of the vulva, expression of MMP-12 by tumor cells correlates with invasiveness, whereas expression of MMP-12 by tumor-infiltrating macrophages predicts a better outcome.

\section{Study Limitations}

The current study has several limitations. First, the web-based tool that we used (1) only provides partial access to the characteristics of the population analyzed and thus limits the potential to report all the considerations for choosing the clinical parameters in the univariable and multivariable Cox regression analysis; (2) does not provide the distribution of data for each parameter in the analysis; (3) does not permit performing analysis with multilevel 
ordinal categoric variables; and (4) does not measure cancer-specific survival. Second, the in vivo model that we used is based on lung cancer cell lines that may differ in their characteristics from primary human and murine lung cancers. Yet, because we focus our research on the interaction of tumor-derived MMP-12 with the native lung microenvironment, we consider the methodology applied in this study to be appropriate and informative. Finally, in the current study, MMP-12 was knocked out in 1 lung cancer cell line. Repeating the experiments in multiple cell lines and mice stains may increase the robustness of the phenomena observed.

\section{CONCLUSIONS}

In the current work, we provide evidence in support of the concept that MMP-12 drives tumor propagation in the lung. We show that once induced in tumor cells, MMP-12 promotes tumor growth and invasiveness regardless of the expression of MMP-12 by other cellular components of the tumor's microenvironment. Given that the expression of MMP-12 in homeostasis is relatively limited and mainly restricted to activated macrophages, we propose that MMP-12 may be a novel therapeutic target in the context of lung tumorigenesis. Further studies looking at the therapeutic potential of targeting MMP-12 in the setting of primary malignancies of the lung are warranted. (Video 1 summarizes the key findings of this study.)

\section{Webcast}

You can watch a Webcast of this AATS meeting presentation by going to: https://aats.blob.core.windows.net/media/17AM/ 2017-05-02/RM306/05-02-17_Room306_0800_Wald.mp4.

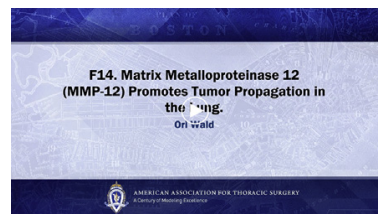

\section{Conflict of Interest Statement}

Authors have nothing to disclose with regard to commercial support.

\section{References}

1. Van Doren SR. Matrix metalloproteinase interactions with collagen and elastin. Matrix Biol. 2015;44-46:224-31.

2. Lagente V, Le Quement C, Boichot E. Macrophage metalloelastase (MMP-12) as a target for inflammatory respiratory diseases. Expert Opin Ther Targets. 2009; 13:287-95.

3. Turino GM, Ma S, Lin YY, Cantor JO, Luisetti M. Matrix elastin: a promising biomarker for chronic obstructive pulmonary disease. Am J Respir Crit Care Med. 2011;184:637-41.

4. Eide HA, Halvorsen AR, Sandhu V, Fane A, Berg J, Haakensen VD, et al. Nonsmall cell lung cancer is characterised by a distinct inflammatory signature in serum compared with chronic obstructive pulmonary disease. Clin Transl Immunology. 2016;5:e109.

5. Shah SA, Spinale FG, Ikonomidis JS, Stroud RE, Chang EI, Reed CE. Differential matrix metalloproteinase levels in adenocarcinoma and squamous cell carcinoma of the lung. J Thorac Cardiovasc Surg. 2010;139:984-90.

6. Demedts IK, Morel-Montero A, Lebecque S, Pacheco Y, Cataldo D, Joos GF, et al. Elevated MMP-12 protein levels in induced sputum from patients with COPD. Thorax. 2006;61:196-201.

7. Acuff HB, Sinnamon M, Fingleton B, Boone B, Levy SE, Chen X, et al. Analysis of host- and tumor-derived proteinases using a custom dual species microarray reveals a protective role for stromal matrix metalloproteinase-12 in non-small cell lung cancer. Cancer Res. 2006;66:7968-75.

8. Hofmann HS, Bartling B, Simm A, Murray R, Aziz N, Hansen G, et al. Identification and classification of differentially expressed genes in non-small cell lung cancer by expression profiling on a global human 59.620-element oligonucleotide array. Oncol Rep. 2006;16:587-95.

9. Hofmann HS, Hansen G, Richter G, Taege C, Simm A, Silber RE, et al. Matrix metalloproteinase-12 expression correlates with local recurrence and metastatic disease in non-small cell lung cancer patients. Clin Cancer Res. 2005;11:1086-92.

10. Cho NH, Hong KP, Hong SH, Kang S, Chung KY, Cho SH. MMP expression profiling in recurred stage IB lung cancer. Oncogene. 2004;23:845-51.

11. Lv FZ, Wang JL, Wu Y, Chen HF, Shen XY. Knockdown of MMP12 inhibits the growth and invasion of lung adenocarcinoma cells. Int J Immunopathol Pharmacol. 2015;28:77-84.

12. Houghton AM, Grisolano JL, Baumann ML, Kobayashi DK, Hautamaki RD, Nehring LC, et al. Macrophage elastase (matrix metalloproteinase-12) suppresses growth of lung metastases. Cancer Res. 2006;66:6149-55.

13. Qu P, Yan C, Du H. Matrix metalloproteinase 12 overexpression in myeloid lineage cells plays a key role in modulating myelopoiesis, immune suppression, and lung tumorigenesis. Blood. 2011;117:4476-89.

14. Qu P, Du H, Wang X, Yan C. Matrix metalloproteinase 12 overexpression in lung epithelial cells plays a key role in emphysema to lung bronchioalveolar adenocarcinoma transition. Cancer Res. 2009;69:7252-61.

15. Gyorffy B, Surowiak P, Budczies J, Lanczky A. Online survival analysis software to assess the prognostic value of biomarkers using transcriptomic data in nonsmall-cell lung cancer. PLoS One. 2013;8:e82241.

16. Weiss ID, Ella E, Dominsky O, Smith Y, Abraham M, Wald H, et al. In the hun for therapeutic targets: mimicking the growth, metastasis, and stromal associations of early-stage lung cancer using a novel orthotopic animal model. J Thorac Oncol. 2015;10:46-58.

17. Gresner P, Gromadzinska J, Wasowicz W. Reference genes for gene expression studies on non-small cell lung cancer. Acta Biochim Pol. 2009;56:307-16.

18. Chung IC, Chen LC, Chung AK, Chao M, Huang HY, Hsueh C, et al. Matrix metalloproteinase 12 is induced by heterogeneous nuclear ribonucleoprotein $\mathrm{K}$ and promotes migration and invasion in nasopharyngeal carcinoma. BMC Cancer. 2014; $14: 348$.

19. Kwon CH, Moon HJ, Park HJ, Choi JH, Park DY. S100A8 and S100A9 promotes invasion and migration through p38 mitogen-activated protein kinase-dependent NF-kappaB activation in gastric cancer cells. Mol Cells. 2013;35:226-34.

20. Wan Z, Jiang D, Chen S, Jiao J, Ji L, Shah AS, et al. T-box transcription factor brachyury promotes tumor cell invasion and metastasis in non-small cell lung cancer via upregulation of matrix metalloproteinase 12. Oncol Rep. 2016;36: 306-14.

21. Wang P, Chen SH, Hung WC, Paul C, Zhu F, Guan PP, et al. Fluid shear promotes chondrosarcoma cell invasion by activating matrix metalloproteinase 12 via IGF2 and VEGF signaling pathways. Oncogene. 2015;34:4558-69.

22. Woenckhaus M, Klein-Hitpass L, Grepmeier U, Merk J, Pfeifer M, Wild P, et al Smoking and cancer-related gene expression in bronchial epithelium and nonsmall-cell lung cancers. J Pathol. 2006;210:192-204.

23. Kerkela E, Ala-Aho R, Jeskanen L, Rechardt O, Grenman R, Shapiro SD, et al Expression of human macrophage metalloelastase (MMP-12) by tumor cells in skin cancer. J Invest Dermatol. 2000;114:1113-9.

24. Kerkela E, Ala-aho R, Klemi P, Grenman S, Shapiro SD, Kahari VM, et al. Metalloelastase (MMP-12) expression by tumour cells in squamous cell carcinoma of the vulva correlates with invasiveness, while that by macrophages predicts better outcome. J Pathol. 2002;198:258-69.

Key Words: lung, non-small cell lung cancer, orthotopic animal model, tumor microenvironment 


\section{Discussion}

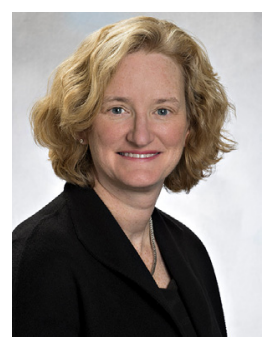

Dr Y. Colson (Boston, Mass). You have nicely investigated the potential role of MMP-12 in lung cancer progression, mainly invasion, and you have postulated a role for it as a therapeutic target. You have shown roughly 3 aspects of what you have investigated, quite elegantly, actually. First is in characterizing MMP-12 expression and localization in tissue samples, and in gene array databases you have ubiquitous expression in NSCLC with the exception of the bronchoalveolar, and the association of MMP-12 mRNA in tumors with reduced survival. Did this association hold true for protein expression and mRNA given the multiple factors that affect actual protein expression?

Dr Ori Wald (Houston, Tex). The mRNA data were extracted from published databases, and I have not looked at databases that report protein expression. There are some published works that used different methodologies and reported that more aggressive lung cancers show higher MMP-12 expression.

Dr Colson. Do you think a lack of MMP-12 expression in the bronchoalveolar subtype is directly related to the decrease in invasiveness that you see or do you think it is due to the fact that the bronchoalveolar is a T1 N0 and it is a lower stage?

Dr Wald. Some people have reported that MMP-12 is actually protective against tumor propagation in the lung, and we report the opposite, of course. I think that MMP12 acts in multiple ways in the tumor microenvironment, and that one of these is indeed by promoting tumor invasion. Nonetheless, other MMPs, such as MMP-2 and MMP-9, may be relevant in the process of tumor invasion.

Another option is that MMP-12 may act as a transcription factor. Two years ago, there was a Nature Medicine article reporting on the role of MMP-12 in protection against viral infection in the lung. This repost indicated that MMP acts intracellularly as a transcription factor. We have not looked into this in our work. I assume though that acquisition of MMP-12 expression by tumor cells or premalignant cells may foster processes that make the tumor more aggressive. This assumption is supported in part by analysis that we have done and indicates that MMP-12 mRNA levels most accurately predict recurrence in early-stage lung cancer.

Dr Colson. Can you hypothesize why you think your data are different than other results that have been reported?

Dr Wald. Well, other people related the inhibition of tumor growth to inhibition of angiogenesis in the lung. I think the lung is highly enriched by vasculature, and I am not certain how much angiogenesis is needed. Further, the work that has shown that MMP-12 is protective against lung cancer did not detect MMP-12 expression by tumor cells. When we tried their model, which is more of a lung metastasis model (because it is based on intravenous injection of tumor cells), we did detect MMP-12 expression in the tumors; therefore, I think our experimental systems significantly differ.

Dr Colson. You have now shown that you are seeing it in tumor as opposed to the lung parenchyma, which is one of the differences you have talked about. Given this association of MMP-12 expression in chronic obstructive pulmonary disease (COPD) and now also the tumor, your model doesn't really talk about that potential interaction of the different MMPs in patients who have COPD who then get lung cancer, right? So there is the potential that there are 2 different drivers of MMP-12 expression in a patient with COPD who also has lung cancer. Do you think there is going to be interaction between them? Do you think that patients get lung cancer more likely because they have COPD or that the COPD gets worse?

Dr Wald. There are several publications reporting that in premalignant lung lesions derived from the lungs of patients with COPD and of smokers, MMP-12 is expressed. This may indicate that long exposure to smoke and other toxins may eventually somehow drive the overexpression of MMP-12 in premalignant lung lesions.

Our model is different, of course. We use cell lines that, on the one hand, we can manipulate, but we didn't test this in conjunction, for example, with exposure to smoke and see whether that would drive faster growth of the cells. Potentially it can be done; however, the cell line that we used, the LLC, is very aggressive, so it would maybe wiser to do it with cells that do not grow so fast in the lung. But potentially it is possible.

Dr Colson. It is just an interesting thought that if you are expressing more at baseline you could do that.

Dr Wald. Thank you for bringing up this point.

Dr Colson. You demonstrated that the knockouts of MMP-12, on the tumor, not the immune cells, reduced the tumor invasiveness, but the proliferation remains roughly the same for the tumor. Is it just the invasiveness that you see is different, and so in vivo you get smaller but not absent tumors?

Dr Wald. That's right.

Dr Colson. In terms of using MMP-12 as a potential therapeutic target, what agents are available? How do you propose that gets used in a setting where you don't completely ablate the tumor, so you are going to have to use other agents?

Dr Wald. First, the issue of specificity is an issue here, and, of course, multiple trials have been done in the past with MMP inhibitors that are not specific and were not successful in preventing cancer progression.

I think that MMP-12 is important early in tumor propagation and that later on other processes prevail. There is one agent today that our collaborators are working with and that has been tested for its potential to 
prevent aortic aneurysm dilatation. This agent is supposed to specifically block MMP-12. However, it acts only extracellularly and does not enter the cells. Such agents may emerge in the future as a relevant drug to test.
For the mean time, we should drill more on the mechanisms before making further comments, and we should continue to validate the role of MMP-12 at the early phases of lung cancer propagation. 

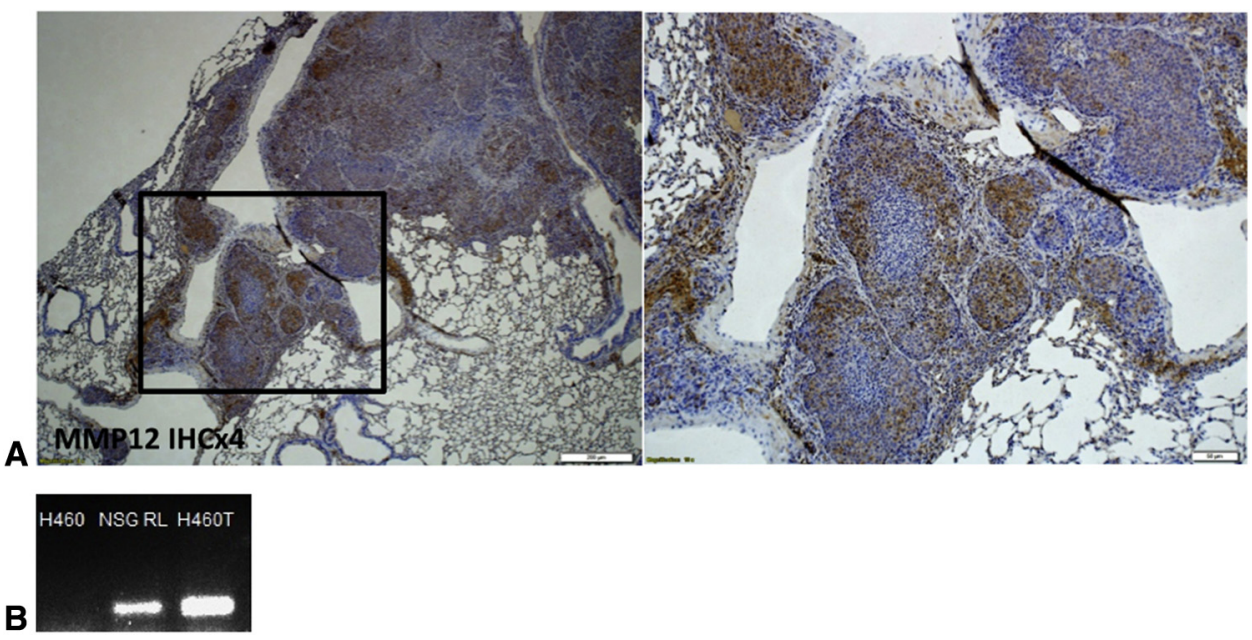

FIGURE E1. MMP-12 expression in H460-induced lung tumors. A, Staining of an H460-derived tumor for MMP-12. Low- and high-power magnifications are shown. B, MMP-12 mRNA expression in H460 cells growing in culture, in lungs of NSG mice, and in H460-derived tumors. MMP-12, Matrix metalloproteinase 12 . 